\title{
Papers
}

\section{Systematic review and meta-analysis of strategies for the diagnosis of suspected pulmonary embolism}

\author{
Pierre-Marie Roy, Isabelle Colombet, Pierre Durieux, Gilles Chatellier, Hervé Sors, Guy Meyer
}

\begin{abstract}
Objectives To assess the likelihood ratios of diagnostic strategies for pulmonary embolism and to determine their clinical application according to pretest probability.

Data sources Medline, Embase, and Pascal Biomed and manual search for articles published from January 1990 to September 2003

Study selection Studies that evaluated diagnostic tests for confirmation or exclusion of pulmonary embolism.

Data extracted Positive likelihood ratios for strategies that confirmed a diagnosis of pulmonary embolism and negative likelihood ratios for diagnostic strategies that excluded a diagnosis of pulmonary embolism.

Data synthesis 48 of 1012 articles were included. Positive likelihood ratios for diagnostic tests were: high probability ventilation perfusion lung scan 18.3 (95\% confidence interval 10.3 to 32.5 ), spiral computed tomography 24.1 (12.4 to 46.7), and ultrasonography of leg veins 16.2 (5.6 to 46.7$)$. In patients with a moderate or high pretest probability, these findings are associated with a greater than $85 \%$ post-test probability of pulmonary embolism. Negative likelihood ratios were: normal or near normal appearance on lung scan 0.05 (0.03 to 0.10 ), a negative result on spiral computed tomography along with a negative result on ultrasonography 0.04 (0.03 to 0.06), and a D-dimer concentration $<500 \mu \mathrm{g} / \mathrm{l}$ measured by quantitative enzyme linked immunosorbent assay 0.08 (0.04 to 0.18 ). In patients with a low or moderate pretest probability, these findings were associated with a post-test probability of pulmonary embolism below 5\%. Spiral computed tomography alone, a low probability ventilation perfusion lung scan, magnetic resonance angiography, a quantitative latex D-dimer test, and haemagglutination D-dimers had higher negative likelihood ratios and can therefore only exclude pulmonary embolism in patients with a low pretest probability.

Conclusions The accuracy of tests for suspected pulmonary embolism varies greatly, but it is possible to estimate the range of pretest probabilities over which each test or strategy can confirm or rule out pulmonary embolism.
\end{abstract}

Topic: $157 ; 295 ; 299$

\section{Introduction}

Pulmonary embolism is a common and serious disease. Clinical signs and symptoms allow the clinician to determine the pretest probability of someone having pulmonary embolism (the clinical probability) but are insufficient to diagnose or rule out the condition. ${ }^{1}$ Laboratory tests and imaging are thus required in all patients with suspected pulmonary embolism. ${ }^{2}$ Since 1990 a large number of diagnostic tests and strategies have been evaluated for pulmonary embolism. As the design, clinical setting, and reference methods differ between studies, the diagnostic value of most tests may seem inconsistent. Although several reviews have been published on this topic, ${ }^{1-3}$ systematic reviews that may clarify the role of the different diagnostic tests are lacking.

We carried out a systematic review to assess the likelihood ratios of the diagnostic tests used for suspected pulmonary embolism. For clinical purposes, we estimated the range of pretest probabilities over which each test can accurately confirm or exclude pulmonary embolism.

\section{Materials and methods}

We searched Medline, Embase, and Pascal Biomed for studies published from January 1990 to September 2003 using the search terms ((pulmonary embol* or pulmonary thromboembol*) and (diagnosis or diagnostic) and (angiography or arteriography or (follow adj up) or followup or (management adj stud*)) and $(\mathrm{PY}=1990-2003)$ and (study or studies or trial) and $(\mathrm{LA}=$ ENGLISH). We also manually searched published bibliographies and our own personal libraries. We retained only studies published in English. We excluded abstracts, editorials, reviews, case reports, and case series.

\section{Data selection}

Two reviewers (PMR, GM) independently selected potentially relevant studies. Studies were included if they evaluated tests or strategies aimed at confirming or excluding pulmonary embolism (confirmation or exclusion diagnostic strategies, respectively) and they met the following criteria: the reference method was pulmonary angiography for confirmation strategies and clinical follow-up or pulmonary angiography for exclusion strategies; the study was prospective; participants were recruited consecutively; and the test being evaluated and the reference test were interpreted independently.

We excluded retrospective studies; follow-up studies with more than $5 \%$ of patients lost to follow-up or those that used additional imaging to pulmonary angiography in patients with a negative experimental test result; studies in which crude data could not be extracted for the calculation of positive and negative likelihood ratios; and studies that had specific populations. Each study was graded according to the reference method and the characteristics of the patients (see table A on

Additional tables and a figure are on bmj.com 
Table 1 Summary of studies evaluating tests or strategies aimed at confirming pulmonary embolism

\begin{tabular}{|c|c|c|c|c|c|c|c|c|}
\hline \multirow[b]{2}{*}{ Diagnostic strategy } & \multicolumn{3}{|c|}{ Study grade } & \multirow[b]{2}{*}{ No of patients } & \multicolumn{3}{|c|}{ Heterogeneity } & \multirow{2}{*}{$\begin{array}{l}\text { Pooled random positive likelihood ratio } \\
\qquad(95 \% \mathrm{Cl})\end{array}$} \\
\hline & A & B & C & & Cochran's Q & $P$ value & $I^{2}(\%)$ & \\
\hline $\begin{array}{l}\text { High probability ventilation-perfusion } \\
\text { lung scan }{ }^{10}\end{array}$ & 0 & 1 & 0 & 881 & - & - & - & $18.3(10.3$ to 32.5$)$ \\
\hline $\begin{array}{l}\text { Perfusion lung scan compatible with } \\
\text { pulmonary embolism }{ }^{11}\end{array}$ & 0 & 0 & 1 & 390 & - & - & - & $7.1(4.6$ to 11.0$)$ \\
\hline \multicolumn{9}{|l|}{ Positive imaging result: } \\
\hline Spiral computed tomography ${ }^{12-17}$ & 2 & 0 & 4 & 431 & 1.39 & 0.93 & 0 & 24.1 (12.4 to 46.7) \\
\hline Leg vein ultrasonography ${ }^{18-21}$ & 0 & 0 & 4 & 378 & 0.52 & 0.92 & 0 & $16.2(5.6$ to 46.7$)$ \\
\hline Echocardiography ${ }^{22} 23$ & 0 & 1 & 1 & 148 & 0.22 & 0.64 & 0 & 5.0 (2.3 to 10.6) \\
\hline Magnetic resonance angiography ${ }^{24-28}$ & 0 & 0 & 5 & 221 & 10.28 & 0.04 & 61 & 11.7 (3.6 to 37.8$)$ \\
\hline
\end{tabular}

bmj.com). For studies with multiple publications, we used data from the most recent publication.

\section{Data extraction}

Two investigators (PMR, GM) independently abstracted data on the design; study size; setting; characteristics of the patients; type of reference standard; and the number of true positive, true negative, false positive, and false negative test results.

When we used follow-up as the reference method, we considered all the patients with a negative test result to have a false negative result if they developed deep vein thrombosis or pulmonary embolism during the three month follow-up period.
We classified deaths believed to be caused by pulmonary embolism as thromboembolic events. When we could not extract data from published articles, we contacted the authors. Discrepancies in data abstraction between investigators were resolved by a third author (PD).

\section{Statistical analysis}

We calculated the positive likelihood ratio for confirmation diagnostic strategies and the negative likelihood ratio for exclusion diagnostic strategies. We used the adjusted Wald method to calculate $95 \%$ confidence intervals. ${ }^{4}$ Summary estimates of the likelihood ratios were calculated as a weighted average, and we

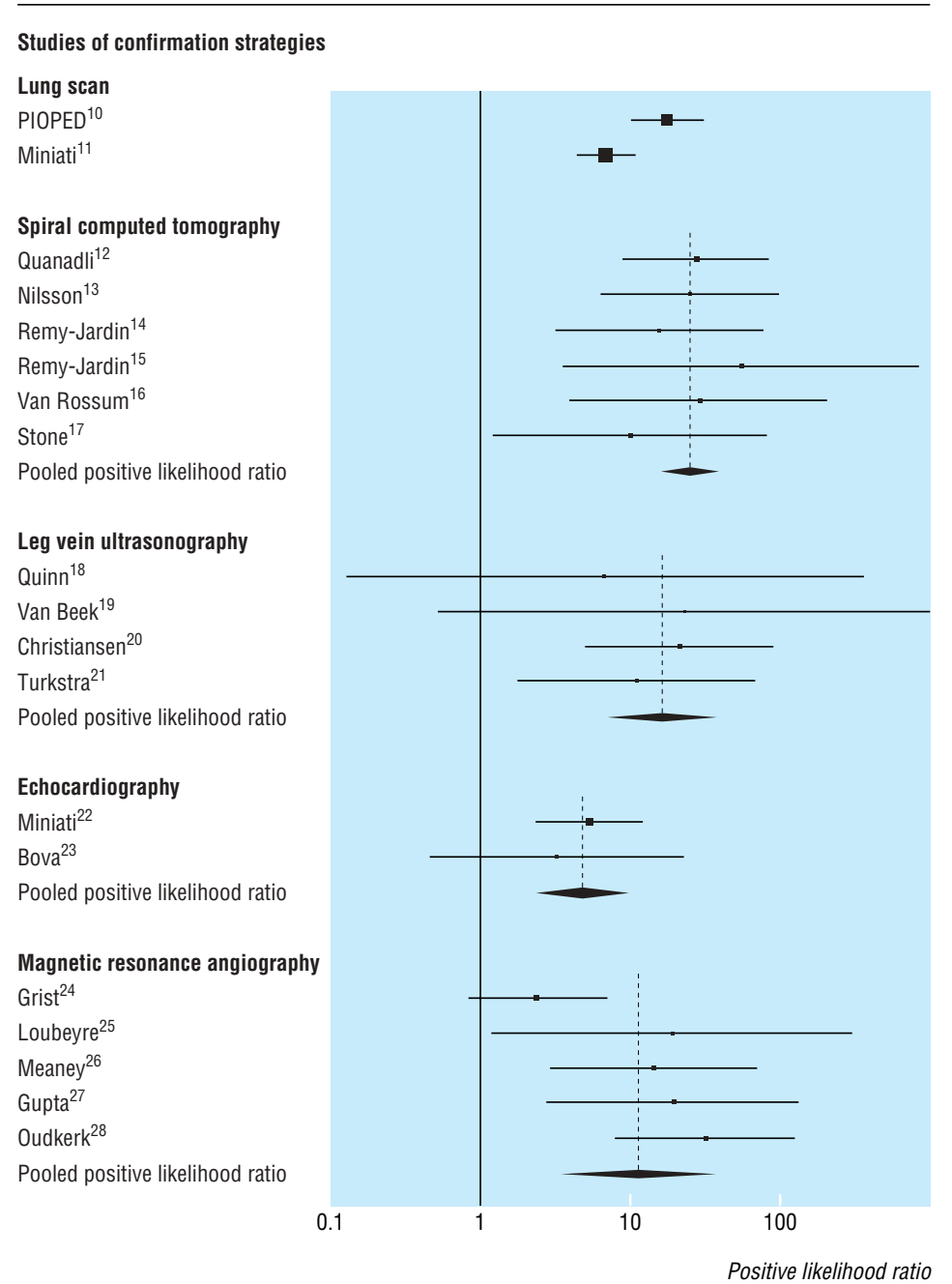

Fig 1 Positive likelihood ratios (squares) and 95\% confidence intervals for strategies used to confirm a diagnosis of pulmonary embolism. Size of square is related to variance of study. Broken line represents pooled positive likelihood ratio, and limits of diamond represents $95 \%$ confidence intervals of pooled ratios 
calculated the confidence intervals using the DerSimonian and Laird random effects method. ${ }^{5}$ Homogeneity tests were carried out to evaluate the consistency of findings across the studies. We used Cochran's $Q$ heterogeneity statistic and the quantity $\mathrm{I}^{2}$ to determine the percentage of total variation across the studies due to heterogeneity rather than to chance. ${ }^{6}$ When $\mathrm{I}^{2}$ was more than $0 \%$, we explored possible reasons for heterogeneity, such as patient populations (selected or unselected patients) and the nature of the reference method (angiography or composite reference standard), using subgroup analysis based on the three categories for study quality (see table A on bmj.com).

Analyses were carried out in STATA (release 6).

\section{Clinical practice perspectives}

We considered that a confirmation strategy was accurate enough to diagnose pulmonary embolism when the post-test probability was above $85 \%$, and that an exclusion strategy was accurate enough to exclude pulmonary embolism when the post-test probability was below $5 \%{ }^{3}$ We used Bayes's theorem to calculate the probability of pulmonary embolism, conditioned by the likelihood ratio as a function of the pretest probability. ${ }^{7}$

\section{Results}

We identified 1012 potentially eligible articles. After scanning the abstracts and titles we screened 93 for possible retrieval. We selected 66 articles for more detailed evaluation; 48 of these were included in the final analysis (see figure on bmj.com). ${ }^{8-55}$ The studies totalled 11004 patients with suspected pulmonary embolism. The condition was confirmed in 3329 patients and excluded in 7675 (prevalence 30\%). We did not analyse studies that used electron beam computed tomography as this technique is no longer used. ${ }^{8}$ See tables B-D on bmj.com for characteristics of the included studies.

\section{Confirmation diagnostic strategies}

Table 1 and figure 1 summarise the confirmation diagnostic strategies and their pooled positive likelihood ratios.

Two studies evaluated lung scintigraphy. ${ }^{10}{ }^{11}$ The prospective investigation of pulmonary embolism diagnosis study assessed the performances of ventilation and perfusion lung scans. ${ }^{10}$ Miniati et al studied the value of a perfusion lung scan without ventilation. ${ }^{11}$ We were unable to pool the results of these two studies as they used different diagnostic criteria and evaluated two different techniques.

We found significant heterogeneity among the five studies on magnetic resonance angiography. ${ }^{2-28}$

\section{Exclusion diagnostic strategies}

Table 2 and figure 2 summarise the exclusion diagnostic strategies and their pooled negative likelihood ratios.

Nine studies analysed the value of a negative result on spiral computed tomography for excluding pulmonary embolism; however, one used a specific definition for negative results. ${ }^{37}$ We detected significant heterogeneity in the study group, but not in the two grade A studies. ${ }^{12} 13$

We found heterogeneity in the group of ultrasonography studies. Five of the six studies were carried out in patients with a non-diagnostic ventilation and perfusion lung scan and one in patients selected on the basis of clinical probability and D-dimer testing. ${ }^{18-21} 42{ }^{43}$ Wells et al studied the negative diagnostic value of serial ultrasonography after a non-diagnostic ventilation and perfusion lung scan. ${ }^{44}$

Table 2 and figure 3 summarise the studies that evaluated D-dimers for the exclusion of pulmonary embolism (see also table D on bmj.com). In the analysis we included 12 studies that evaluated three different quantitative D-dimer enzyme linked immunosorbent assays, including two classic microplate methods $^{45-50} 53$ and one rapid quantitative method. ${ }^{34} 41435152$ One

Table 2 Summary of studies evaluating tests or strategies aimed at excluding pulmonary embolism

\begin{tabular}{|c|c|c|c|c|c|c|c|c|}
\hline \multirow[b]{2}{*}{ Diagnostic strategy } & \multicolumn{3}{|c|}{ Study Grade } & \multirow[b]{2}{*}{ No of patients } & \multicolumn{3}{|c|}{ Heterogeneity } & \multirow{2}{*}{$\begin{array}{c}\text { Pooled random negative likelihooc } \\
\text { ratio }(95 \% \mathrm{Cl})\end{array}$} \\
\hline & A & B & C & & Cochran's Q & $P$ value & $I^{2}(\%)$ & \\
\hline $\begin{array}{l}\text { Normal or near normal radioisotopic } \\
\text { lung scan }{ }^{10} 29-36\end{array}$ & 0 & 5 & 4 & 3170 & 9.53 & 0.30 & 16 & 0.05 (0.03 to 0.10$)$ \\
\hline Subgroup of grade B studies ${ }^{1029-32}$ & & 5 & & 1841 & 6.9 & 0.14 & 42 & $0.06(0.02$ to 0.16$)$ \\
\hline Subgroup of grade C studies ${ }^{33-36}$ & & & 4 & 1329 & 0.60 & 0.90 & 0 & 0.03 (0.01 to 0.09$)$ \\
\hline $\begin{array}{l}\text { Low probability ventilation perfusion } \\
\text { radioisotopic lung scan }{ }^{10}\end{array}$ & 0 & 1 & 0 & 881 & - & - & - & $0.36(0.25$ to 0.50$)$ \\
\hline $\begin{array}{l}\text { Perfusion lung scan not compatible } \\
\text { with pulmonary embolism }{ }^{11}\end{array}$ & 0 & 0 & 1 & 390 & - & - & - & 0.09 (0.06 to 0.15$)$ \\
\hline $\begin{array}{l}\text { Negative spiral computed } \\
\text { tomography }{ }^{12-1737-39}\end{array}$ & 2 & 1 & 6 & 1197 & 13.95 & 0.08 & 35 & $0.11(0.06$ to 0.19$)$ \\
\hline Subgroup of grade A studies ${ }^{12} 13$ & 2 & - & - & 247 & 0.54 & 0.46 & 0 & $0.07 \quad(0.03$ to 0.15$)$ \\
\hline Subgroup of grade C studies ${ }^{14-173839}$ & - & - & 6 & 440 & 7.80 & 0.17 & 36 & $0.15(0.08$ to 0.30$)$ \\
\hline \multicolumn{9}{|l|}{ Negative test results: } \\
\hline $\begin{array}{l}\text { Ultrasonography and spiral } \\
\text { computed tomograpy }^{374041}\end{array}$ & 0 & 1 & 2 & 1863 & 0.10 & 0.95 & 0 & $0.04(0.03$ to 0.06$)$ \\
\hline Leg vein ultrasonography ${ }^{18-21} 4243$ & 0 & 0 & 6 & 731 & 9.72 & 0.08 & 49 & 0.67 (0.50 to 0.89 ) \\
\hline Echocardiography 2223 & 0 & 1 & 1 & 148 & 0.15 & 0.70 & 0 & $0.59(0.41$ to 0.86$)$ \\
\hline $\begin{array}{l}\text { Magnetic resonance } \\
\text { angiography }{ }^{25-28}\end{array}$ & 0 & 0 & 5 & 221 & 1.16 & 0.88 & 0 & $0.20(0.12$ to 0.34$)$ \\
\hline $\begin{array}{l}\text { Quantitative enzyme linked } \\
\text { immunosorbent assay D-dimer } \\
<500 \mu \mathrm{g} / /^{34} 414345-52\end{array}$ & 0 & 4 & 7 & 3368 & 21.9 & 0.02 & 54 & 0.08 (0.04 to 0.18$)$ \\
\hline Subgroup of grade B studies ${ }^{34414546}$ & - & 4 & - & 2375 & 0.473 & 0.93 & 0 & $0.01(0.00$ to 0.04$)$ \\
\hline Subgroup of grade C studies ${ }^{43} 47-52$ & - & - & 7 & 993 & 1.074 & 0.98 & 0 & $0.21 \quad(0.12$ to 0.34$)$ \\
\hline $\begin{array}{l}\text { Quantitative latex D-dimer test }<500 \\
\mu \mathrm{g} / \mathrm{I}^{13} 3655\end{array}$ & 1 & 1 & 1 & 596 & 2.64 & 0.27 & 24 & $0.20(0.10$ to 0.39$)$ \\
\hline $\begin{array}{l}\text { Semiquantitative latex D-dimer test } \\
<500 \mu \mathrm{g} / \mathrm{l}^{49} 54\end{array}$ & 0 & 0 & 2 & 201 & 2.43 & 0.12 & 59 & 0.29 (0.03 to 2.46$)$ \\
\hline $\begin{array}{l}\text { Negative hemagglutination D-dimer } \\
\text { test }^{31} 3551\end{array}$ & 0 & 1 & 2 & 791 & 0.46 & 0.79 & 0 & $0.31(0.18$ to 0.56$)$ \\
\hline
\end{tabular}




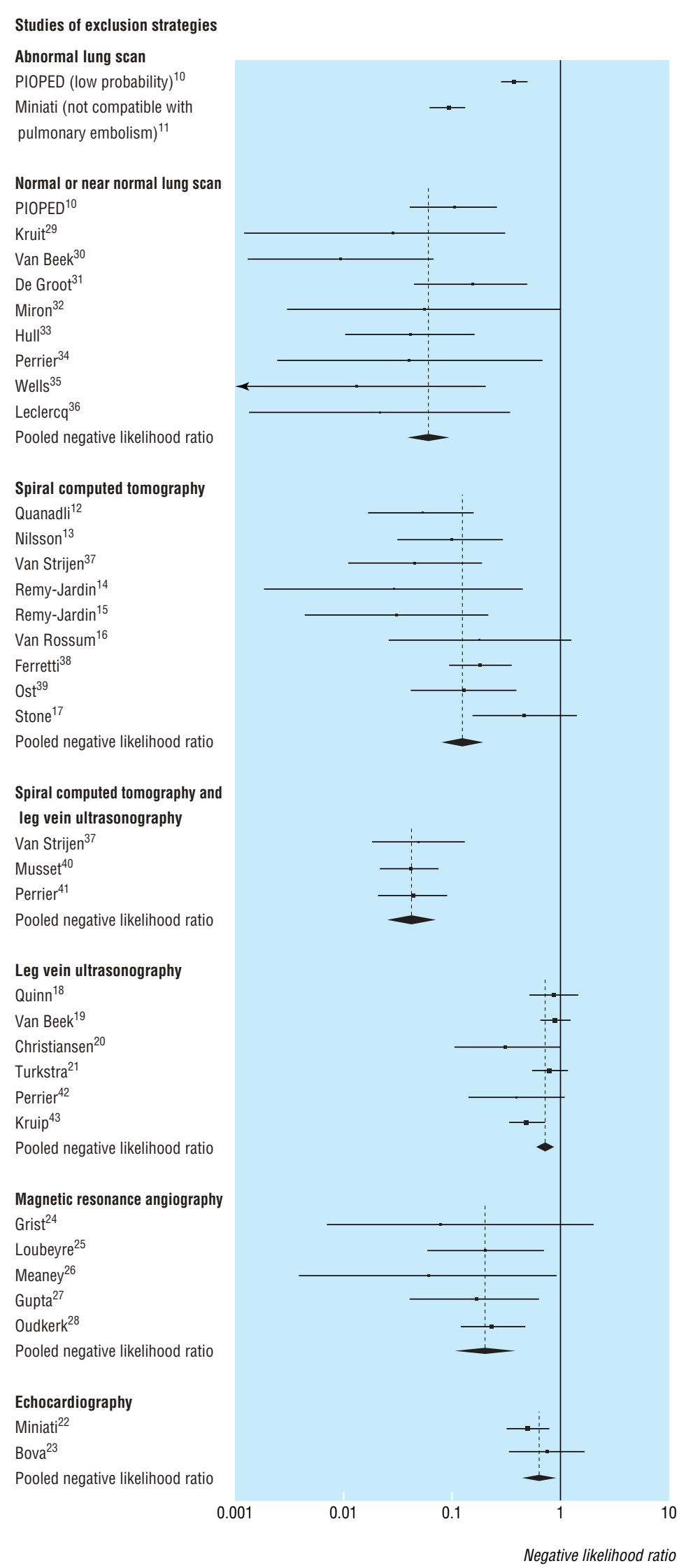

Fig 2 Negative likelihood ratios (squares) and 95\% confidence intervals for strategies used to exclude a diagnosis of pulmonary embolism. Size of square related to variance of study. Broken line represents pooled negative likelihood ratio, and limits of diamond represents $95 \%$ confidence intervals of pooled ratios 


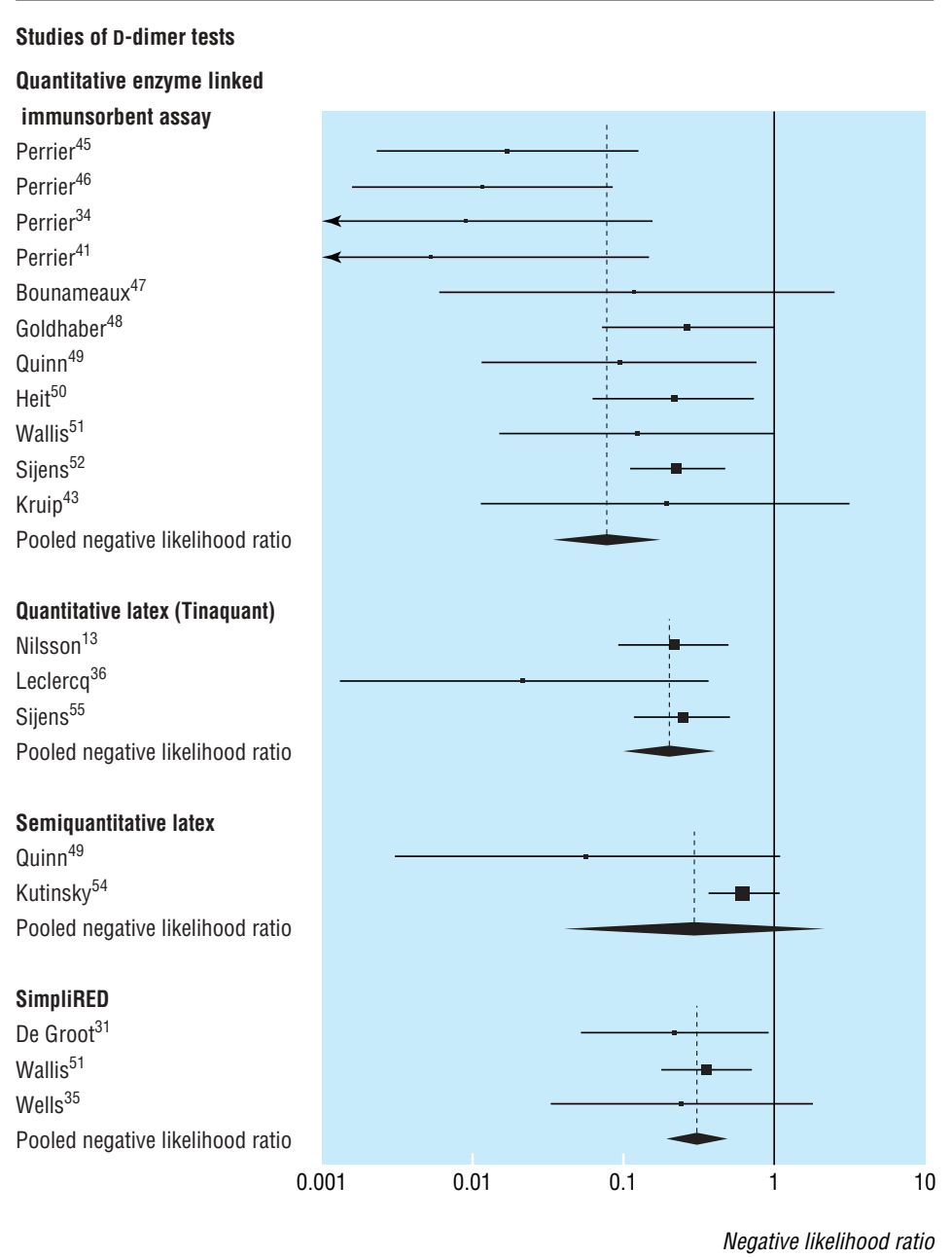

Fig 3 Negative likelihood ratios (squares) and 95\% confidence intervals for strategies used to exclude a diagnosis of pulmonary embolism on basis of D-dimer tests. Size of square is related to variance of study. Broken line represents pooled negative likelihood ratio, and limits of diamond represent $95 \%$ confidence interval of pooled negative likelihood ratio

study used a different cut-off threshold so we excluded it from the calculation of summary negative likelihood ratios. ${ }^{53}$ We detected significant heterogeneity in the study group, but we found no heterogeneity in the grade $B^{34414546}$ or grade C studies. ${ }^{43}{ }^{47-52}$

Studies that used seven different quantitative D-dimer latex agglutination assays met our inclusion criteria. ${ }^{13} 3649505355$ Two studies evaluated several latex D-dimer tests in the same patients so we excluded them from the calculation of summary negative likelihood ratios. ${ }^{49}{ }^{50}$ One study used a different cut-off value so we excluded that from the calculation of the summary negative likelihood ratios too. ${ }^{53}$ Three studies could be pooled. ${ }^{13} 3655$

Two studies that evaluated a semiquantitative agglutination latex assay had significant heterogeneity. ${ }^{49}$ A whole blood agglutination D-dimer assay was evaluated in three studies, with no significant heterogeneity. ${ }^{31}{ }^{35}{ }^{51}$

\section{Clinical practice perspectives}

For each strategy we calculated the post-test probability as a function of the pretest probability (figs 4 and 5). For each diagnostic strategy we express the accuracy of diagnostic decisions as a function of the pretest probability (fig 6).

\section{Relation to pretest probability}

Confirmation of pulmonary embolism

In patients with a high pretest probability; a positive result with spiral computed tomography, ultrasonography, echocardiography, or magnetic resonance angiography; or a high probability ventilation perfusion lung scan are associated with a post-test probability of over $85 \%$, allowing pulmonary embolism to be accurately diagnosed. Patients with a moderate pretest probability require additional imaging after a positive echocardiography result. In patients with a low pretest probability, the post-test probability was below $85 \%$ for all tests and therefore further investigations would be needed to confirm pulmonary embolism (fig 6).

\section{Exclusion of pulmonary embolism}

In patients with a low clinical probability; negative test results for D-dimers or with spiral computed tomography or magnetic resonance angiography; or a normal or low probability lung scan are associated with a post-test probability of below $5 \%$. In this situation, additional testing would not be needed to rule out pulmonary embolism. Conversely, patients with a negative echocardiography result and a normal venous ultrasonography result would require additional testing to rule out pulmonary 

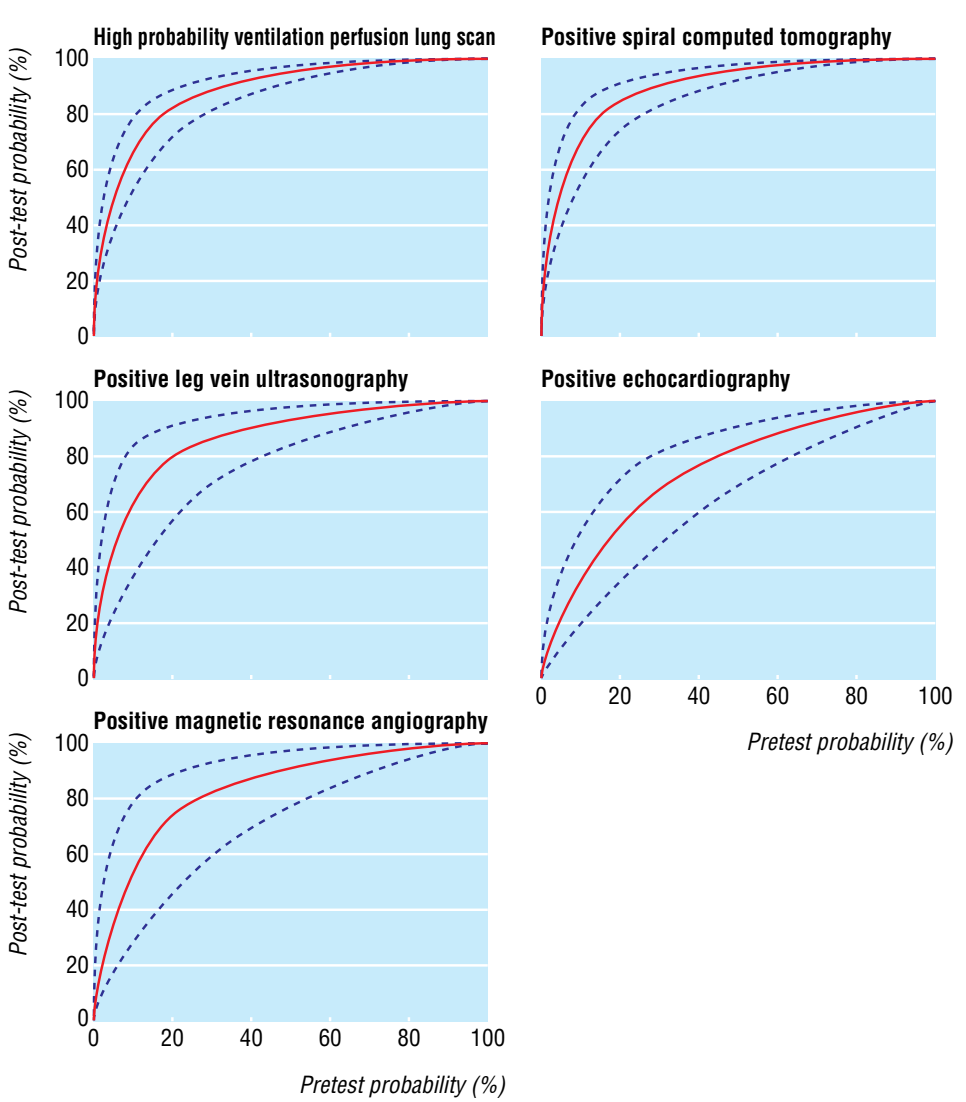

Pretest probability (\%)

Fig 4 Post-test probability according to pre-test probability and pooled values (solid line) or limits of 95\% confidence intervals (broken lines) of the positive likelihood ratio

embolism, even when the clinical probability was low. In patients with a moderate pretest probability, a negative quantitative D-dimer enzyme linked immunosorbent assay result, a normal or near normal lung scan, or a combination of normal spiral computed tomography results and normal venous ultrasonography results accurately exclude pulmonary embolism. In patients with a high pretest probability, the residual post-test probability remained above $5 \%$ for all diagnostic tests (fig 6). In these patients, additional testing would be required to confidently exclude pulmonary embolism.

\section{Discussion}

Large differences exist in the accuracy of diagnostic tests used to confirm or rule out pulmonary embolism. Ventilation perfusion lung scanning, spiral computed tomography, and ultrasonography of the leg veins all had positive likelihood ratios above 10 . When these tests are positive in patients with a moderate or high clinical probability of pulmonary embolism they provide a posttest probability greater than $85 \%$. A normal or near normal ventilation perfusion lung scan result, a combination of spiral computed tomography and ultrasonography, and quantitative D-dimer enzyme linked immunosorbent assay results had negative likelihood ratios below 0.10 and can exclude pulmonary embolism in patients with a low or moderate pretest probability. Spiral computed tomography alone, a low probability ventilation perfusion lung scan, magnetic resonance angiography, the latex Tinaquant D-dimer test, and the haemagglutination D-dimer test have higher negative likelihood ratios and can exclude pulmonary embolism only in patients with a low clinical probability. Echocardiography and ultrasonography seem unable to exclude pulmonary embolism.

The most straightforward approach for determining the accuracy of a diagnostic test is to carry out a cross sectional study in unselected patients, with independent, blinded assessments of test and reference methods. ${ }^{56}$ Our literature search identified only three studies that used such a stringent design in patients with suspected pulmonary embolism. ${ }^{9}{ }^{12} 13$ Pulmonary angiography is the reference method for the diagnosis of pulmonary embolism, but it has the limitations of being an invasive procedure with associated risks, and physicians are reluctant to carry it out in all patients. ${ }^{57}$ Clinical follow-up of untreated patients with negative test results is considered a valuable alternative to this risky reference method, ${ }^{59}$ as the number of symptomatic thromboembolic events during a three month follow-up period without anticoagulant treatment reflects the number of false negative tests. ${ }^{60}$ Nevertheless, inclusion of follow-up studies in our analysis is associated with some drawbacks. Blinding is not maintained and some false negative test results may be undetected. In addition, in most of these studies a positive angiogram was not used to confirm the diagnosis of pulmonary embolism, and the rate of false positive test results may have been miscalculated. However, the criteria used to confirm pulmonary embolism (positive results with computed tomography or ultrasonography, high probability ventilation perfusion lung scan) are widely accepted. ${ }^{23}$

We expressed test performance as likelihood ratios. According to Bayes's theorem, the likelihood ratio indicates the extent of change in the odds of disease after a test result. ${ }^{56}$ Likelihood ratios can be calculated irrespective of the format of the 

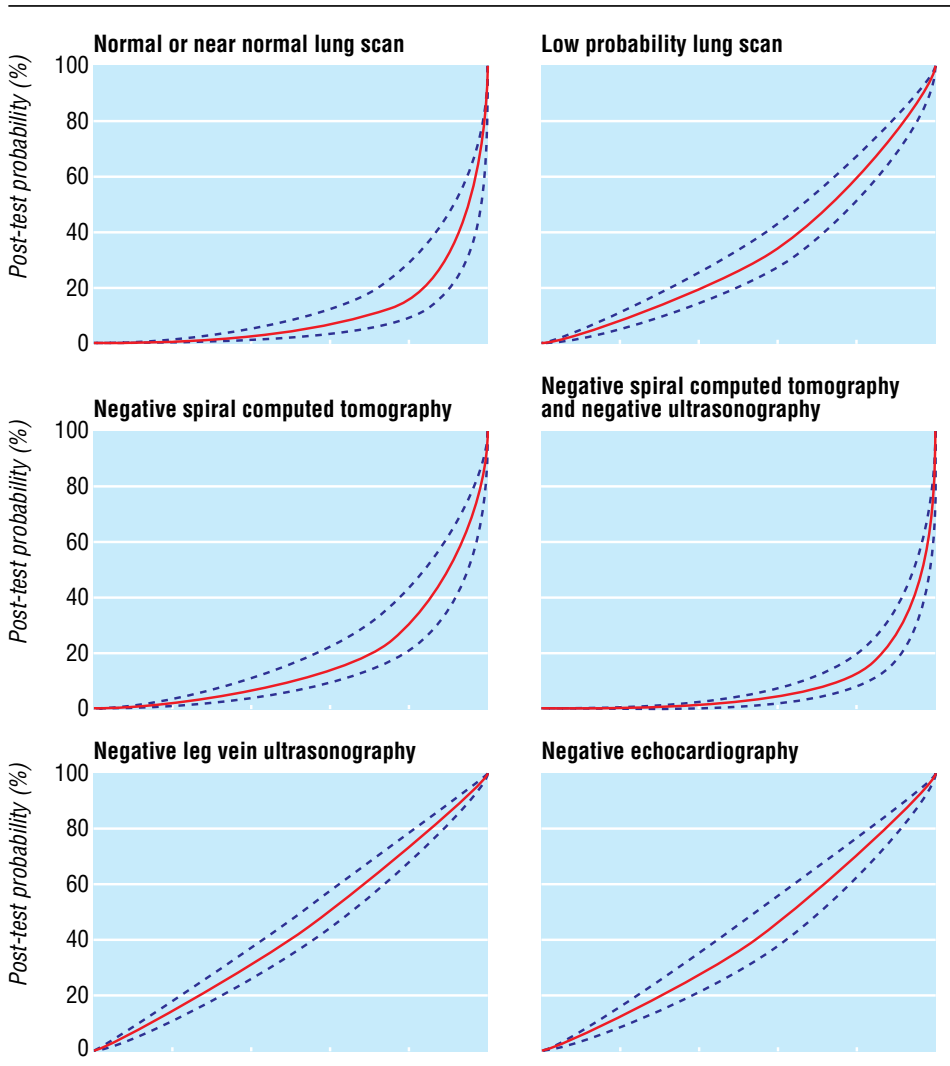

Negative echocardiography
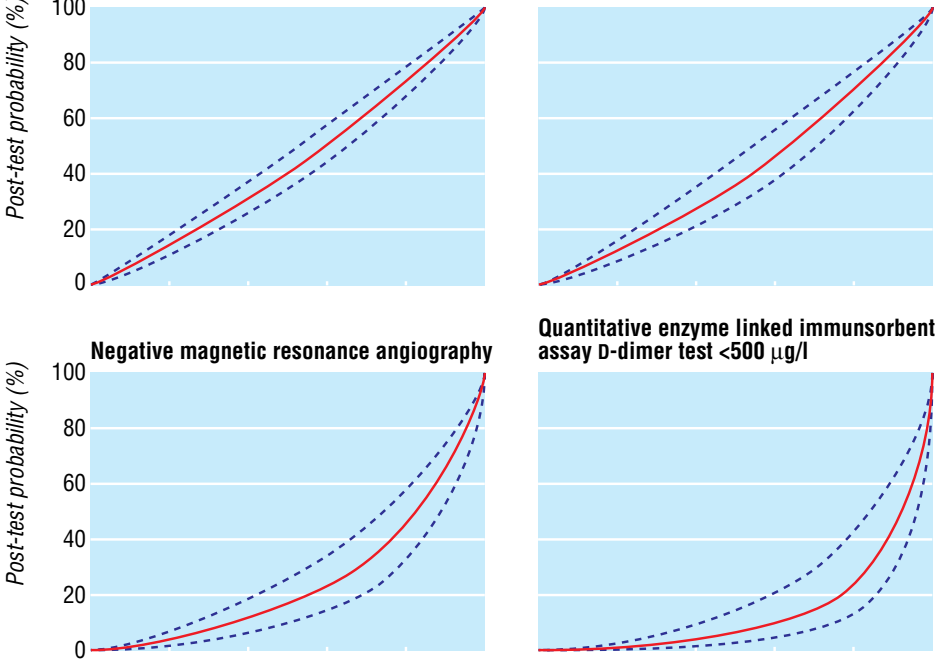

Quantitative enzyme linked immunsorbent assay D-dimer test $<500 \mu \mathrm{g} / \mathrm{l}$
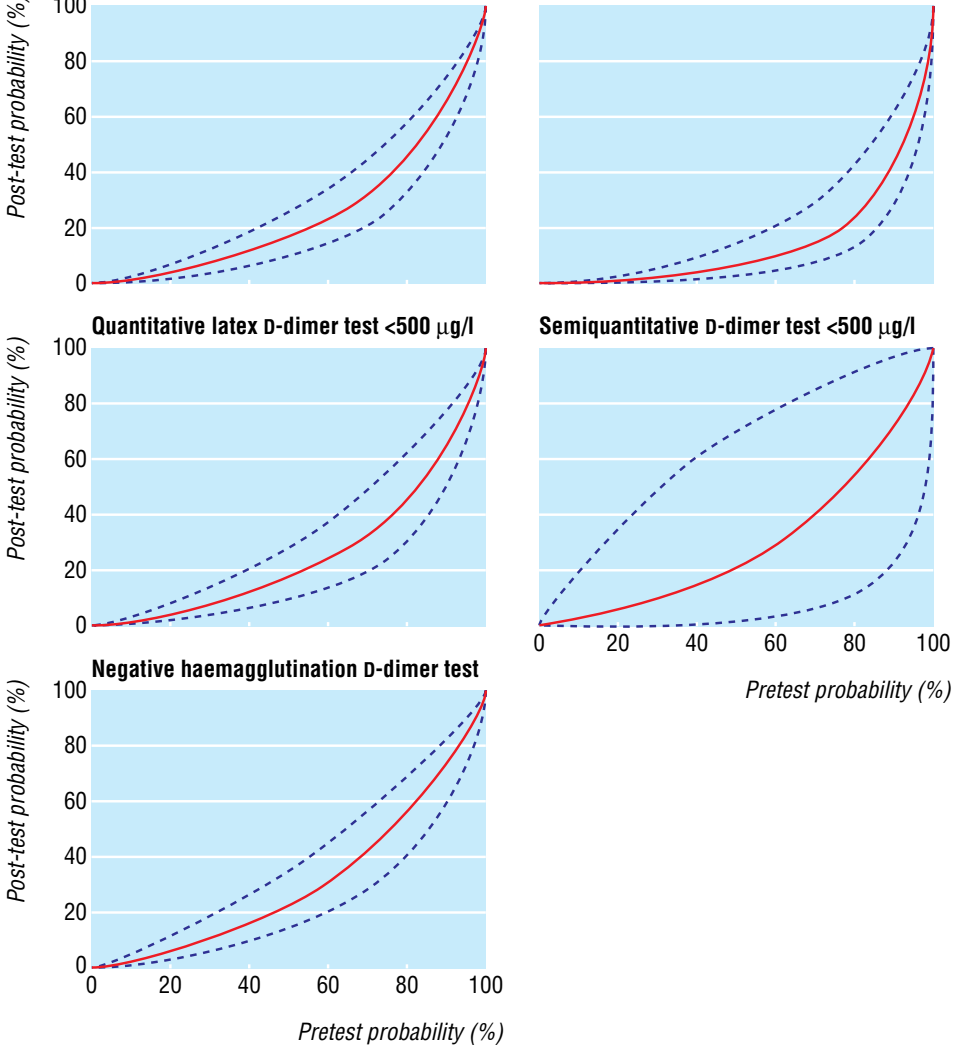

Fig 5 Post-test probability according to pre-test probability and pooled values (solid line) or limit of 95\% confidence intervals (broken lines) of the negative likelihood ratio 


\begin{tabular}{|c|c|c|c|c|c|}
\hline \multicolumn{2}{|c|}{$\begin{array}{l}\text { Low clinical probability } \\
\text { (prevalence of pulmonary embolism }=10 \% \text { ) }\end{array}$} & \multicolumn{2}{|c|}{$\begin{array}{c}\text { Intermediate clinical probability } \\
\text { (prevalence of pulmonary embolism }=35 \% \text { ) }\end{array}$} & \multicolumn{2}{|c|}{$\begin{array}{c}\text { High clinical probability } \\
\text { (prevalence of pulmonary embolism }=70 \% \text { ) }\end{array}$} \\
\hline & & & & & \\
\hline$\downarrow$ & $\downarrow$ & $\downarrow$ & $\downarrow$ & $\downarrow$ & $\downarrow$ \\
\hline $\begin{array}{l}\text { Exclusion of } \\
\text { pulmonary embolism } \\
\text { Negative D-dimer test* } \\
\text { Near or normal lung scan } \\
\text { Low probability } \\
\text { ventilation-perfusion } \\
\text { lung scan } \\
\text { Negative spiral computed } \\
\text { tomography result } \\
\text { Negative magnetic } \\
\text { resonance angiography } \\
\text { result }\end{array}$ & $\begin{array}{l}\text { Confirmation of } \\
\text { pulmonary embolism }\end{array}$ & $\begin{array}{l}\text { Exclusion of } \\
\text { pulmonary embolism } \\
\text { Quantitative enzyme } \\
\text { linked immunosorbent } \\
\text { assay } \\
\text { D-dimer test }<500 \mu \mathrm{g} / \mathrm{l} \\
\text { Normal or near normal } \\
\text { lung scan } \\
\text { Negative spiral computed } \\
\text { tomography and negative } \\
\text { leg vein ultrasonography } \\
\text { result }\end{array}$ & $\begin{array}{l}\text { Confirmation of } \\
\text { pulmonary embolism } \\
\text { Positive leg vein } \\
\text { ultrasonography result } \\
\text { High probability } \\
\text { ventilation-perfusion } \\
\text { lung scan } \\
\text { Positive spiral computed } \\
\text { tomography result } \\
\text { Positive magnetic } \\
\text { resonance angiography } \\
\text { result }\end{array}$ & $\begin{array}{l}\text { Exclusion of } \\
\text { pulmonary embolism }\end{array}$ & $\begin{array}{l}\text { Confirmation of } \\
\text { pulmonary embolism } \\
\text { Positive } \\
\text { echocardiography result } \\
\text { Positive leg vein } \\
\text { ultrasonography result } \\
\text { High probability } \\
\text { ventilation-perfusion } \\
\text { lung scan } \\
\text { Positive spiral computed } \\
\text { tomography result } \\
\text { Positive magnetic } \\
\text { resonance angiography } \\
\text { result }\end{array}$ \\
\hline Negative angiography & Positive angiography & Negative angiography & Positive angiography & Negative angiography & Positive angiography \\
\hline
\end{tabular}

Fig 6 Diagnostic tests for pulmonary embolism that allow accurate exclusion (post-test probability $<5 \%$ ) and accurate confirmation of the condition (post-test probability $>85 \%$ ) for three levels of clinical probability. Pulmonary angiography is reference method and is supposed to rule in or rule out pulmonary embolism for all values of clinical probability

test result: dichotomous (spiral computed tomography, ultrasonography, magnetic resonance angiography, qualitative D-dimer test), ordinal (ventilation perfusion lung scan), or continuous (quantitative D-dimer tests).

Some of our findings are limited by the low number of studies meeting our quality criteria, especially those of lung scanning. Systematic reviews of diagnostic studies are hampered by the heterogeneity of results, even when attempts to define the most homogeneous set of studies are made, as in our study. ${ }^{61}$ In studies dealing with quantitative D-dimer enzyme linked immunosorbent assay results, the negative likelihood ratio of grade $\mathrm{B}$ studies were homogeneous but lower than those of grade $\mathrm{C}$ studies. This discrepancy may be explained by differences in the study population and by the use of pulmonary angiography as the reference method in most grade $\mathrm{C}$ studies as opposed to follow-up in most grade B studies. Pulmonary angiography is difficult to interpret in patients selected on the basis of a previous lung scan result (grade $\mathrm{C}$ studies), leading to a high risk of mis-

\section{What is already known on this topic}

The accuracy of diagnostic tests for suspected pulmonary embolism varies largely between studies, and the appropriate clinical setting for their use is unclear

\section{What this study adds}

When the clinical probability is moderate or high, pulmonary embolism is confirmed by a high probability lung scan and a positive result on spiral computed tomography or venous ultrasonography

When clinical probability is low, these results require confirmation by pulmonary angiography

In patients with a low or moderate clinical probability, the condition can be excluded by a negative quantitative D-dimer test result, a normal or near normal lung scan, or normal findings on spiral computed tomography and venous ultrasonography

When clinical probability is high, these results require confirmation by pulmonary angiography classification. $^{19}$ These patients are also likely to have small pulmonary emboli, which may increase the rate of false negative D-dimer test results. ${ }^{52}$

As proposed by Kearon, we assumed that the diagnosis of pulmonary embolism was accurate when the post-test probability was above $85 \%$ and that pulmonary embolism could be safely ruled out when the risk of venous thromboembolism was below $5 \%{ }^{3}$ We defined a range of pretest probabilities at which each test can confirm or rule out pulmonary embolism, with an acceptable risk of misdiagnosis (fig 6). As a general rule, the results suggest that discordance between clinical probability and the diagnostic test result requires additional studies.

Our findings allow the calculation of the post-test probability of pulmonary embolism provided that the pretest probability has been estimated before the test. Our results also suggest that the performances of several diagnostic tests remain poorly defined and need additional evaluation.

Contributors: GM had the idea for the study; he is guarantor for the paper. PMR, GM, and PD designed the study. PMR and GM assessed the studies for inclusion, extracted the data, and drafted the paper. IC, GC, and HS provided advice on interpretation of the results. IC did the statistical analysis. All authors revised the paper critically and approved the final manuscript.

Funding: None.

Competing interests: None declared.

Ethical approval: Not required.

1 Chunilal SD, Eikelboom JW, Attia J, Miniati M, Panju AA, Simel DL, et al. Does this patient have pulmonary embolism? JAMA 2003;290:2849-58.

Fedullo PF, Tapson VF. Clinical practice. The evaluation of suspected pulmonary embolism. N Engl J Med 2003;349:1247-56.

Kearon C. Diagnosis of pulmonary embolism. CMAJ 2003;168:183-94.

4 Agresti A, Coull BA. Order-restricted tests for stratified comparisons of binomial proportions. Biometrics 1996;52:1103-11.

DerSimonian R. Meta-analysis in the design and monitoring of clinical trials. Stat Med 1996;15:1237-52.

6 Higgins JP, Thompson SG, Deeks JJ, Altman DG. Measuring inconsistency in meta-analyses. BMJ 2003;327:557-60.

7 Diamond GA, Forrester JS. Analysis of probability as an aid in the clinical diagnosis of coronary-artery disease. N Engl J Med 1979;300:1350-8.

8 Teigen CL, Maus TP, Sheedy PF 2nd, Stanson AW, Johnson CM, Breen JF, et al. Pulmonary embolism: diagnosis with contrast-enhanced electron-beam CT and comparison with pulmonary angiography. Radiology 1995;194:313-9.

9 Boonbaichaiyapruck S, Panpunnang S, Siripornpitak S, Nitjapanich S, Sritara C, Sritara P. Utilization of electron beam CT scan in diagnosis of pulmonary embolism. J Med Assoc Thai 1997:80:527-33.

10 PIOPED Investigators. Value of the ventilation/perfusion scan in acute pulmonary embolism. Results of the prospective investigation of pulmonary embolism diagnosis embolism. Results of the prospective investigation of pulmonar
(PIOPED). The PIOPED Investigators. JAMA 1990;263:2753-9.

11 Miniati M, Pistolesi M, Marini C, Di Ricco G, Formichi B, Prediletto R, et al. Value of perfusion lung scan in the diagnosis of pulmonary embolism: results of the prospective 
investigative study of acute pulmonary embolism diagnosis (PISA-PED). Am J Respir Crit Care Med 1996; 154:1387-93.

12 Qanadli SD, Hajjam ME, Mesurolle B, Barre O, Bruckert F, Joseph T, et al. Pulmonary embolism detection: prospective evaluation of dual-section helical CT versus selective pulmonary arteriography in 157 patients. Radiology 2000;217:447-55

13 Nilsson T, Soderberg M, Lundqvist G, Cederlund K, Larsen F, Rasmussen E, et al. A comparison of spiral computed tomography and latex agglutination D-dimer assay in acute pulmonary embolism using pulmonary arteriography as gold standard. Scand Cardiovasc J 2002;36:373-7.

14 Remy-Jardin M, Remy J, Wattinne L, Giraud F. Central pulmonary thromboembolism diagnosis with spiral volumetric CT with the single-breath-hold techniquecomparison with pulmonary angiography. Radiology 1992;185:381-7.

15 Remy-Jardin M, Remy J, Deschildre F, Artaud D, Beregi JP, Hossein-Foucher C, et al. Diagnosis of pulmonary embolism with spiral CT: comparison with pulmonary angiography and scintigraphy. Radiology 1996;200:699-706.

16 Van Rossum AB, Treurniet FE, Kieft GJ, Smith SJ, Schepers-Bok R. Role of spiral volumetric computed tomographic scanning in the assessment of patients with clinical suspicion of pulmonary embolism and an abnormal ventilation/perfusion lung scan Thorax 1996;51:23-8.

17 Stone E, Roach P, Bernard E, Briggs G, Havryk A, Faulder K, et al. Use of computed tomography pulmonary angiography in the diagnosis of pulmonary embolism in patients with an intermediate probability ventilation/perfusion scan. Intern Med J
$2003: 33: 74-8$.

18 Quinn RJ, Nour R, Butler SP, Glenn DW, Travers PL, Wellings G, et al. Pulmonary embolism in patients with intermediate probability lung scans: diagnosis with Doppler

19 Van Beek EJ, Reekers JA, Batchelor DA, Brandjes DP, Buller HR. Feasibility, safety and clinical utility of angiography in patients with suspected pulmonary embolism. Eur Radiol 1996;6:415-9.

20 Christiansen F, Kellerth T, Andersson T, Ragnarsson A, Hjortevang F. Ultrasound at scintigraphic "intermediate probability of pulmonary embolism." Acta Radio $1996 ; 37: 14-7$

21 Turkstra F, Kuijer PM, van Beek EJ, Brandjes DP, ten Cate JW, Buller HR. Diagnostic utility of ultrasonography of leg veins in patients suspected of having pulmonary embolism. Ann Intern Med 1997;126:775-81.

22 Miniati M, Monti S, Pratali L, Di Ricco G, Marini C, Formichi B, et al. Value of transthoracic echocardiography in the diagnosis of pulmonary embolism: results of a prospecracic echocardiography in the diagnosis of pulmonary embo
tive study in unselected patients. Am J Med 2001;110:528-35.

23 Bova C, Greco F, Misuraca G, Serafini O, Crocco F, Greco A, et al. Diagnostic utility of echocardiography in patients with suspected pulmonary embolism. Am J Emerg Med 2003;21:180-3.

24 Grist TM, Sostman HD, MacFall JR, Foo TK, Spritzer CE, Witty L, et al. Pulmonary angiography with MR imaging: preliminary clinical experience. Radiology 1993; 189:523-30.

25 Loubeyre P, Revel D, Douek P, Delignette A, Baldy C, Genin G, et al. Dynamic contrastenhanced MR angiography of pulmonary embolism: comparison with pulmonary angiography. Am J Roentgenol 1994;162:1035-9.

26 Meaney JF, Weg JG, Chenevert TL, Stafford-Johnson D, Hamilton BH, Prince MR. Diagnosis of pulmonary embolism with magnetic resonance angiography. N EnglJ Med Diagnosis of pulm

27 Gupta A, Frazer CK, Ferguson JM, Kumar AB, Davis SJ, Fallon MJ, et al. Acute pulmonary embolism: diagnosis with MR angiography. Radiology 1999;210:353-9.

28 Oudkerk M, van Beek EJ, Wielopolski P, van Ooijen PM, Brouwers-Kuyper EM, Bongaerts $\mathrm{AH}$, et al. Comparison of contrast-enhanced magnetic resonance angiography and conventional pulmonary angiography for the diagnosis of pulmonary embolism: a prospective study. Lancet 2002;359:1643-7.

29 Kruit WH, de Boer AC, Sing AK, van Roon F. The significance of venography in the management of patients with clinically suspected pulmonary embolism.J Intern Med 1991;230:333-9.

30 Van Beek EJ, Kuijer PM, Buller HR, Brandjes DP, Bossuyt PM, ten Cate JW. The clinical course of patients with suspected pulmonary embolism. Arch Intern Med course of patie
$1997 ; 157: 2593-8$.

31 De Groot MR, van Marwijk Kooy M, Pouwels JG, Engelage AH, Kuipers BF, Buller HR. The use of a rapid D-dimer blood test in the diagnostic work-up for pulmonary embolism: a management study. Thromb Haemost 1999;82:1588-92.

32 Miron MJ, Perrier A, Bounameaux H, de Moerloose P, Slosman DO, Didier D, et al. Contribution of noninvasive evaluation to the diagnosis of pulmonary embolism in hospitalized patients. Eur Respir J 1999;13:1365-70.

33 Hull RD, Raskob GE. Low-probability lung scan findings: a need for change. Ann Intern Med 1991;114:142-3.

34 Perrier A, Desmarais S, Miron MJ, de Moerloose P, Lepage R, Slosman D, et al. Non-invasive diagnosis of venous thromboembolism in outpatients. Lancet 1999:353:190-5.

35 Wells PS, Anderson DR, Rodger M, Stiell I, Dreyer JF, Barnes D, et al. Excluding pulmonary embolism at the bedside without diagnostic imaging: management of patients with suspected pulmonary embolism presenting to the emergency department by using a simple clinical model and D-dimer. Ann Intern Med 2001;135:98-107.

36 Leclercq MG, Lutisan JG, van Marwijk Kooy M, Kuipers BF, Oostdijk AH, van der Leur $\mathrm{JJ}$, et al. Ruling out clinically suspected pulmonary embolism by assessment of clinical probability and D-dimer levels: a management study. Thromb Haemost 2003;89:97-103.

37 Van Strijen MJ, de Monye W, Schiereck J, Kieft GJ, Prins MH, Huisman MV, et al. Single-detector helical computed tomography as the primary diagnostic test in suspected pulmonary embolism: a multicenter clinical management study of 510 patients. Ann Intern Med 2003;138:307-14

38 Ferretti GR, Bosson JL, Buffaz PD, Ayanian D, Pison C, Blanc F, et al. Acute pulmonary embolism: role of helical CT in 164 patients with intermediate probability at ventilation-perfusion scintigraphy and normal results at duplex US of the legs. Radiolventilation-perfusion $1997 ; 205: 453-8$.

39 Ost D, Rozenshtein A, Saffran L, Snider A. The negative predictive value of spiral computed tomography for the diagnosis of pulmonary embolism in patients with nondiagnostic ventilation-perfusion scans. Am J Med 2001;110:16-21.
40 Musset D, Parent F, Meyer G, Maitre S, Girard P, Leroyer C, et al. Diagnostic strategy for patients with suspected pulmonary embolism: a prospective multicentre outcome study. Lancet 2002;360:1914-20.

41 Perrier A, Roy PM, Aujesky D, Chagnon I, Howarth N, Gourdier AL, et al. Diagnosing pulmonary embolism in outpatients with clinical assessment, D-dimer measurement, venous ultrasound, and helical computed tomography: a multicenter managemen study. Am J Med 2004;116:291-9.

42 Perrier A, Miron MJ, Desmarais S, de Moerloose P, Slosman D, Didier D, et al. Using clinical evaluation and lung scan to rule out suspected pulmonary embolism: is it a valid option in patients with normal results of lower-limb venous compression valid option in patients with normal results of
ultrasonography? Arch Intern Med 2000;160:512-6.

43 Kruip MJ, Slob MJ, Schijen JH, van der Heul C, Buller HR. Use of a clinical decision rule in combination with D-dimer concentration in diagnostic workup of patients with suspected pulmonary embolism: a prospective management study. Arch Intern Med 2002;162:1631-5.

44 Wells PS, Ginsberg JS, Anderson DR, Kearon C, Gent M, Turpie AG, et al. Use of a clinical model for safe management of patients with suspected pulmonary embolism. Ann Intern Med 1998;129:997-1005.

45 Perrier A, Bounameaux H, Morabia A, de Moerloose P, Slosman D, Didier D, et al. Diagnosis of pulmonary embolism by a decision analysis-based strategy including clinical probability, D-dimer levels, and ultrasonography: a management study. Arch Intern Med 1996;156:531-6.

46 Perrier A, Desmarais S, Goehring C, de Moerloose P, Morabia A, Unger PF, et al. D-dimer testing for suspected pulmonary embolism in outpatients. Am J Respir Crit Care Med 1997;156:492-6.

47 Bounameaux H, Schneider PA, Slosman D, de Moerloose P, Reber G. Plasma D-dimer in suspected pulmonary embolism: a comparison with pulmonary angiography and ventilation-perfusion scintigraphy. Blood Coagul Fibrinolysis 1990;1:577-9.

48 Goldhaber SZ, Simons GR, Elliott CG, Haire WD, Toltzis R, Blacklow SC, et al. Quantitative plasma D-dimer levels among patients undergoing pulmonary angiography for suspected pulmonary embolism. JAMA 1993;270:2819-22.

49 Quinn DA, Fogel RB, Smith CD, Laposata M, Taylor Thompson B, Johnson SM, et al. D-dimers in the diagnosis of pulmonary embolism. Am J Respir Crit Care Med D-dimers in the

50 Heit JA, Minor TA, Andrews JC, Larson DR, Li H, Nichols WL. Determinants of plasma fibrin D-dimer sensitivity for acute pulmonary embolism as defined by pulmonary angiography. Arch Pathol Lab Med 1999;123:235-40.

51 Wallis JW, Kruip M, de Jongh-Leuvenink J, Buller HR. A comparative study of two rapid D-dimer tests for the exclusion of pulmonary embolism in symptomatic patients. Thromb Haemost 2000;84:925.

52 Sijens PE, van Ingen HE, van Beek EJ, Berghout A, Oudkerk M. Rapid ELISA assay for plasma D-dimer in the diagnosis of segmental and subsegmental pulmonary embolism. A comparison with pulmonary angiography. Thromb Haemost 2000;84:156-9.

53 Heit JA, Meyers BJ, Plumhoff EA, Larson DR, Nichols WL. Operating characteristics of automated latex immunoassay fibrin D-dimer tests in the diagnosis of angiographically-defined acute pulmonary embolism. Thromb Haemost 2000;83:970.

54 Kutinsky I, Blakley S, Roche V. Normal D-dimer levels in patients with pulmonary embolism. Arch Intern Med 1999;159:1569-72.

55 Sijens PE, Oudkerk M, Berghout A, van Ingen HE, Kemperman H. Comparison of a quantitative latex and a quantitative ELISA plasma D-dimer assay in the exclusion of segmental and subsegmental pulmonary embolism. Thromb Haemost 2001;86:1580-2.

56 Jaeschke R, Guyatt G, Sackett DL. Users' guides to the medical literature. III. How to use an article about a diagnostic test. A. Are the results of the study valid? Evidence-Based Medicine Working Group. JAMA 1994;271:389-91.

57 Nilsson T, Carlsson A, Mare K. Pulmonary angiography: a safe procedure with modern contrast media and technique. Eur Radiol 1998;8:86-9.

58 Stein PD, Athanasoulis C, Alavi A, Greenspan RH, Hales CA, Saltzman HA, et al. Complications and validity of pulmonary angiography in acute pulmonary embolism. Circulation 1992;85:462-8.

59 Sackett DL, Haynes RB. The architecture of diagnostic research. In: Library B, ed. The evidence base of clinical diagnosis. London: BMJ Books 2002:19-38.

60 Kruip MJ, Leclercq MG, van der Heul C, Prins MH, Buller HR. Diagnostic strategies for excluding pulmonary embolism in clinical outcome studies. A systematic review. Ann Intern Med 2003;138:941-51.

61 Deeks IJ. Systematic reviews in health care: systematic reviews of evaluations of diagnostic and screening tests. BMJ 2001;323:157-62.

(Accepted 27 May 2005)

bmj.com 2005;331:259

Emergency Department, Centre Hospitalier Universitaire, 49033 Angers cedex 01,

France

Pierre-Marie Roy physician

Department of Clinical Epidemiology, INSERM U 729, Université Paris V,

Assistance Publique Hopitaux de Paris, Hôpital Européen Georges Pompidou,

Paris, France

Isabelle Colombet physician

Pierre Durieux physician

Gilles Chatellier professor

Department of Respiratory and Intensive Care, Université Paris V

Herv Sors professor

Guy Meyer professor

Correspondence to: G Meyer, Service de Pneumologie-soins intensifs, Hôpital

Européen Georges Pompidou, 20 rue Leblanc, 75015 Paris, France

guy.meyer@hop.egp.ap-hop-paris.fr 